\title{
Gerd-Rainer Horn, The Spirit of Vatican II Western European Progressive Catholicism in the Long Sixties
}

Oxford, Oxford University Press, 2015, 264 p.

Pascale Gruson

\section{(2) OpenEdition Journals}

\section{Édition électronique}

URL : http://journals.openedition.org/assr/28372

DOI : $10.4000 /$ assr.28372

ISSN : $1777-5825$

\section{Éditeur}

Éditions de l'EHESS

Édition imprimée

Date de publication : 31 décembre 2016

Pagination : 319

ISSN : 0335-5985

Référence électronique

Pascale Gruson, « Gerd-Rainer Horn, The Spirit of Vatican II Western European Progressive Catholicism in the Long Sixties ", Archives de sciences sociales des religions [En ligne], 176 | octobredécembre 2016, mis en ligne le 20 juillet 2017, consulté le 24 septembre 2020. URL : http:// journals.openedition.org/assr/28372; DOI : https://doi.org/10.4000/assr.28372

Ce document a été généré automatiquement le 24 septembre 2020.

(C) Archives de sciences sociales des religions 


\title{
Gerd-Rainer Horn, The Spirit of Vatican II Western European Progressive Catholicism in the Long Sixties
}

Oxford, Oxford University Press, 2015, 264 p.

\author{
Pascale Gruson
}

\section{RÉFÉRENCE}

Gerd-Rainer Horn, The Spirit of Vatican II Western European Progressive Catholicism in the Long Sixties, Oxford, Oxford University Press, 2015, 264 p.

1 Le Concile Vatican II (1962-1965), convoqué par Jean XXIII peu de temps après son élection, a été un événement. En effet, sa visée profondément œcuménique portait une volonté d'ouverture au monde, une attention aux modalités du développement social (ses acquis, ses injustices, ses horizons), qui en ont surpris plus d'un dans l'Église comme dans la société séculière. Elle marquait de plus une décrispation vis-à-vis des grands ennemis qu'avaient été, pour Pie XII, le communisme et l'athéisme. Or dans le même temps, il y avait, dans le monde séculier, une effervescence d'initiatives et de mouvements sociaux. Ils interrogeaient les problèmes surgis de l'évolution de la Guerre froide ou des diverses modalités de la décolonisation. Ils dénonçaient des choix politiques qui, dans l'euphorie d'une croissance retrouvée, d'un capitalisme à nouveau conquérant (la montée en puissance entre autres des entreprises multinationales), semblaient avoir encore oublié que le progrès technique n'est pas en soi vecteur de progrès social. Beaucoup avaient pris naissance dans le monde universitaire, alors en profonde transformation et inquiet de certaines réformes très exclusivement utilitaristes ou de certains usages des ressources de connaissance. Dans sa disposition 
d'esprit, le Concile pouvait partager ces inquiétudes et ces questions venues du monde séculier.

Ces dynamiques se sont rencontrées. Mais comment ? Et qu'en est-il résulté de manière concrète plus ou moins durable? C'est ce que Gerd-Rainer Horn, fin connaisseur de cette période, permet d'appréhender dans un livre tout à fait passionnant.

3 Les travaux du Concile devaient donc porter sur la mission de l'Église dans le monde. La volonté d'ouverture a alors été immédiatement perceptible puisque la rédaction des documents préparatoires en fut confiée, entre autres, au père Yves Congar et au père Marie-Dominique Chenu. Le geste n'était pas anodin, puisque ces théologiens avaient été écartés de toute responsabilité sous le pontificat de Pie XII, au prétexte qu'ils étaient trop proches des catholiques progressistes (trop proches en particulier des prêtres-ouvriers découvrant sur leurs lieux de travail que leur mission d'évangélisation ne pouvait que prendre un sens assez différent de celui qui leur avait été indiqué).

D'emblée, les deux dominicains ont rapporté le thème de la mission à celui de l'ecclésiologie. Qu'est-ce que l'Église chargée d'annoncer l'espérance du Christ? Comment l'Église peut-elle envisager cette charge ? Comment et selon quels critères cette responsabilité peut-elle se déployer? Reprenant la définition selon laquelle l'Église est le peuple de Dieu, ils ont souligné la polysémie de l'expression : le peuple de Dieu est à la fois corps mystique du Christ et assemblée de laïcs. L'espace ainsi tracé est alors compris comme un espace dans lequel les décisions d'action supposent une véritable collégialité. C'est ce problème qui a été soumis à l'attention des pères conciliaires : pour mettre en œuvre la mission qui leur est confiée par le Christ, quelles responsabilités des évêques, quelles responsabilités des laïcs? Quels modes d'approches des problèmes du monde vécu?

On le sait, après le concile, il y a eu des changements très marqués : les laïcs ont été reconnus dans une beaucoup plus grande autonomie; ils ont entre autres pu avoir un accès direct à la lecture de la Bible. Les évêques ont été encouragés à la collégialité dans les conférences nationales, afin d'être plus autonomes dans leur prise en charge de problèmes propres à des situations locales. Et il est apparu que l'espérance eschatologique n'était rien sans une approche anthropologique des réalités du monde vécu, sans prendre la mesure dans le hic et nunc des injustices, des difficultés, des souffrances.

Les débats du Concile ont donné lieu à la rédaction de deux documents, Lumen Gentium et Gaudium et Spes. Associés à l'encyclique Pacem in Terris (1963) qui s'adressait, de manière tout à fait inhabituelle, non pas aux fidèles, mais au monde, ils ont impressionné le monde séculier. Si les documents eux-mêmes ont été rédigés de manière subtilement contrôlée, conservant à l'autorité pontificale des attributs décisifs (dont celle-ci n'a pas manqué d'user par la suite, au moins jusqu'à l'élection du pape François), ils ont ouvert la voie à d'importantes initiatives. Du côté de «l'assemblée des laïcs", les moindres ne sont pas le développement de nombreux mouvements associatifs. Ces formations, parce qu'elles sont souples, parce qu'elles peuvent être très réactives aux urgences locales, apparaissent le plus souvent comme des relais remarquables aux politiques publiques. Ce fut le cas par exemple à Florence au temps de la gestion du maire Giorgio La Pira. Du côté des évêques, les conférences nationales ont permis d'engager des réflexions audacieuses, par exemple en France, les travaux de la commission Justice et Paix. 
7 Il y a eu aussi, dans la mouvance du Concile et comme le souligne Horn, un renouveau de la réflexion et des débats théologiques, et ce non seulement dans l'Église catholique, mais aussi chez les protestants. Et ces travaux, ceux de Karl Rahner, de Jean-Baptiste Metz, de Jurgen Moltmann et de bien d'autres ont alors rencontré des questions philosophiques nées de la réflexion sur les apories de la modernité, telles que les paroxysmes violents des deux guerres mondiales les avaient mis en évidence. En parallèle, les réflexions de certains philosophes (Walter Benjamin, Ernst Bloch, École de Francfort) fondaient aussi les références qui permettaient aux mouvements étudiants de contester certaines formes de transmission du savoir ou de formation professionnelle. Manifestement un lien actif s'est constitué entre les deux mondes et les étudiants catholiques s'y sont largement engagés, notamment en France.

8 Sans doute considère-t-on maintenant et au vu de l'actualité présente que tous ces mouvements, dans l'Église et dans le monde séculier, avaient une dimension un peu naïve, se retrouvant dans une sensibilité de gauche qui n'évitait pas des références idéologiques que l'on fuit plutôt dans le monde contemporain. Souvent on prend en exemple les déconvenues qui ont succédé à des grandes espérances : la théologie de la libération se serait fourvoyée ici ou là; les utopies des mouvements étudiants se seraient révélées, in fine, peu soucieuses de démocratie. Mais est-ce si évident?

9 L'auteur note que les catholiques bretons, plutôt très conservateurs jusqu'au Concile, ont profondément changé leur vision du monde. Au-delà de ce fait particulier notable, il suggère de prendre en considération le rayonnement concret de cette effervescence des années 1960, mue par l'espérance d'une vie en commun plus amicale. C'est le développement des mouvements associatifs qui, même s'ils ont de réelles limites parce que leur horizon d'action est borné par d'inévitables contingences, se poursuit encore ; ce sont les communautés de base et leur rayonnement, tel celui de la communauté San Egidio ; ce sont aussi les ONG, ce qui n'est manifestement pas le moins important dans notre présent!

Reste toutefois une interrogation. Ces initiatives et les travaux qu'elles ont suscités, n'ont-ils jamais pu porter au débat public les questions nées de l'opacité des interdépendances, des réserves de violence que contiennent les rapports sociaux ? La lecture de ce livre passionnant par sa démarche et par les informations qu'il rassemble incite à poser cette question. 